\title{
Creencias protestantes, estrategias gitanas. El evangelismo de las iglesias de Filadelfia en el Sur de España
}

\author{
Manuela Cantón Delgado \\ Dpto. de Antropología Social. \\ Universidad de Sevilla
}

\section{RESUMEN}

Las conversiones de gitanos al protestantismo evangélico constituyen, desde hace ya más de cuatro décadas, el más importante movimiento religioso, social y político en la compleja historia de este pueblo. Este artículo aborda el pentecostalismo gitano de las iglesias de Filadelfia a partir de una contextualización histórica y etnográfica, para centrarse posteriormente en la presentación de dos narraciones cruzadas que evocan el surgimiento de la primera iglesia evangélica gitana en Andalucía, impulsada por la presencia de dos predicadores franceses. Esta primera congregación se forma en un barrio marginal de Sevilla, y las voces de sus miembros históricos nos permiten imaginar cómo fueron las primeras reuniones en los años sesenta del pasado siglo. El artículo desarrolla asimismo algunas reflexiones sobre los usos socio-políticos de las conversiones gitanas al pentecostalismo en los contextos etnográficos explorados (Sevilla y Cádiz).

Palabras clave: Religión pentecostal, Gitanos, Narrativas, Procesos políticos.

\section{SUMMARY}

Since four decades, the conversions of gypsies to evangelical Protestantism are the most important religious, social and political movement in the complex history of this people. This article approaches gipsy Pentecostalism of the Philadelphia Churches starting from its ethnographical and historical context, to focuse on the representation of two crossed narratives which describe the beginning of the first gipsy evangelical church in Andalusia. This first evangelical community was formed in a marginal district of Sevilla city. These religious meetings were started by two french preachers that propagated the new bornagain religion among the andalusian gypsies. Furthermore, this article developed some ideas about the social and political uses of the gipsy conversion to Pentecostalism in the ethnographical context of our fieldwork, developed in Sevilla and Cadiz.

Key words: Pentecostal Religion, Gypsies, Narratives, Political Processes.

RDTP, LVIII, 2 (2003): 179-200 


\begin{abstract}
Aquellos gitanos franceses que nos predicaron en Sevilla nos parecian unos locos... con sus carromatos, con su elocuencia. Pero traian un mensaje nuevo, hablaban de corazón a corazón, de pobre a pobre, de gitano a gitano (Nicolás Pisa, pastor gitano)
\end{abstract}

Más que tratar de dibujar una caracterización completa del evangelismo gitano en Andalucía, me he propuesto en estas páginas un objetivo más modesto, aunque tal vez más interesante para quienes ya están familiarizados con el tema que nos ocupa. Es un propósito doble: por un lado, y tras la introducción de algunos datos de carácter histórico y etnográfico, me ocuparé de esbozar una memoria de los orígenes, tejida a partir de dos voces gitanas que nos permiten imaginar cómo fueron aquellos primeros cultos evangélicos de los años sesenta, iniciados por dos gitanos franceses en un barrio marginal de Sevilla. Por otro lado, apuntaré algunas reflexiones para entender los usos socio-políticos de las conversiones gitanas en los contextos gitano-andaluces estudiados.

\title{
LUGARES TEÓRICOS Y CONTEXTOS ETNOGRÁFICOS
}

Si el pentecostalismo vino a impregnar con sus carismas y milagros ese mundo desencantado al que se refirió Max Weber, no sin cierta amargura (Weber 1996: 200), el evangelismo gitano reencanta al pentecostalismo mismo. Las iglesias pentecostales, o carismáticas, nacen del metodismo norteamericano que, contrariamente al calvinismo, que encontraba engañoso todo lo sentimental, sostenía que el único fundamento de la certeza de la salvación descansaba en el sentimiento, en la emoción sentida, "en la seguridad absoluta del agraciado, en tanto que era sentida por él, derivada del testimonio directo del Espíritu" (Weber 1989: 118-129, 186-187). El pentecostalismo nace como oposición a la institucionalización del impulso renovador que arrancó con la Reforma europea, y sus orígenes concretos hay que buscarlos en la Iglesia Metodista fundada por John Wesley en el siglo XVIII ${ }^{1}$.

\footnotetext{
${ }^{1}$ El metodismo, corriente pietista escindida del anglicanismo, toma cuerpo tras afincarse Wesley en Estados Unidos. Su énfasis en la separación de los santificados (bautizados en el Espíritu Santo) y los cristianos comunes, así como en la observancia de un rigor ético extremo que prohibía expresamente entregarse a ninguna clase de diversión "mundana", le llevó a separarse de la iglesia madre de Inglaterra en 1799. Salvacionistas, nazarenos, asambleas de Dios y pentecostales, adoptaron esta tradición de "santidad" de origen wesleyano, y empezaron a organizarse en torno a estos principios en California en 1867, formando grupos de oración para devolver a las congre-
} 
$\mathrm{Al}$ igual que el metodismo, del que se escinde, los pentecostales rechazan la doctrina de la predestinación calvinista, según la cual los individuos están por completo en manos de los designios divinos, que ya han previsto sus destinos antes de la creación del mundo. Y ello porque el pentecostalismo nace de ese "pragmatismo ético" promovido por los "avivamientos" del siglo XIX en los Estados Unidos, que buscaba devolver la responsabilidad de la salvación a los mismos individuos. De la misma manera, ha sido espectacular la evolución experimentada por las formas más ascéticas de la ética y el ritual protestantes: pensemos, por ejemplo, que la aparente rigidez fundamentalista del pentecostalismo se ve contrapesada por su carácter carismático, la sensualidad y la emoción de las experiencias rituales, marcadas por la "presencia del Espíritu Santo" que, como describen los mismos creyentes, "me baja", "me llena", "me posee", hasta llevar al baile, al trance, al desmayo. En los cultos pentecostales abundan las manifestaciones de tipo extático, la liberación (exorcismo), la imposición de manos para recibir sanidad, las profecías, el don de lenguas o glosolalia. Desgajado de las Asambleas de Dios francesas, podemos afirmar que las bases doctrinales y los modos rituales del evangelismo gitano son en esencia pentecostales, o lo que es lo mismo, con origen en ciertas formas del metodismo norteamericano de finales del siglo $\mathrm{XIX}$ y principios del XX. El pentecostalismo reencanta al protestantismo ascético, enfrenta ese "desencantamiento del mundo" del que hablara Weber, desafía la "inaudita soledad interior" del calvinista. Y, sin duda, el evangelismo gitano ha venido a reencantar al pentecostalismo.

Llegado a Andalucía en los años sesenta, lo que hoy podemos llamar el evangelismo gitano-andaluz es el resultado de la apropiación, por parte de los gitanos, de una de las más importantes denominaciones en la historia del protestantismo - la pentecostal - y su adaptación a contextos socio-culturales propios. No es casual que haya sido precisamente la corriente pentecostal con la que más se han identificado grupos muy diversos de gitanos españoles. Pensemos que ha sido, probablemente, la opción ideológica y religiosa que ha permitido crear nuevos espacios en los que apenas se producen contradicciones entre las nuevas coordenadas marcadas por la religión pentecostal y el modo de vida gitano: su sentido de la movilidad, la libertad y la autonomía, su concepto de la centralidad de la familia y el respeto a los mayores, la oralidad de sus procesos de transmisión cultural, la pasión por la música y el baile, su sentido de la fiesta. Los gitanos evangélicos han logra-

gaciones el fervor y la pureza primitivos y, emulando el episodio bíblico de Pentecostés, para pedir la manifestación del Espíritu Santo y sus "lenguas de fuego", lo que desembocaría en el sello distintivo de las iglesias pentecostales: el don de lenguas o glosolalia (ver Hechos, 2: 1-4). 
do hacer compatible su manera de ser con la adopción de un conjunto preciso de reglas de conducta que modifica más —es mi tesis- aquello que desune a los gitanos, que lo que les une. A lo largo de los últimos cuarenta años se han ido levantando un número espectacular de templos, capillas, iglesias, cultos $^{2}$ por toda Andalucía que, llevados en su mayoría por pastores gitanos $^{3}$, vienen funcionando como espacios de hibridación cultural y de gestión desde dentro de las consecuencias más dramáticas de los procesos de cambio, y como espacios de lucha contra la exclusión social, política, económica, religiosa y simbólica.

Contrariamente a lo que sostienen los agentes más críticos con el evangelismo gitano -que lo consideran una respuesta simbólica de los marginados que sólo consigue perpetuar su exclusión-, la adscripción a las nuevas agrupaciones religiosas desborda los escenarios chabolistas y marginales, ya que las conversiones se registran entre todos los sectores sociales y económicos de esta minoría étnica. Aunque acaso anecdóticos, podemos citar los casos de célebres personajes del mundo artístico (flamenco) gitano que se declaran evangélicos. No obstante, nuestro trabajo tiene como protagonistas a gitanos de condición humilde, habitantes de polígonos urbanos degradados que son el resultado del desarrollismo de la década de 1960 y sus efectos en el urbanismo, zonas en estado de creciente abandono, marcadas por la exclusión más desesperada. El hacinamiento de familias en bloques de pisos en condiciones extremas, es lo que se ha dado en llamar "chabolismo vertical". Son nuestros protagonistas porque los gitanos pobres siguen siendo la mayoría estadística en Andalucía, pese a que, muy especialmente desde la jerarquía del pastorado gitano, se eleven voces que lamentan esa visión simplificadora del gitano como pobre, inculto y marginado. En nuestro propio trabajo hemos encontrado reticencias a lo que ellos imaginan como una identificación apresurada y contraproducente entre evangelismo gitano y marginalidad. Pero siguen siendo los sectores mayoritarios en el mundo gitano y, en consecuencia, los sectores mayoritarios entre los mismos aleluyas.

La vitalidad de las iglesias y las conversiones aceleradas de familias enteras de gitanos de la Baja Andalucía pueden ser atribuidas a multitud de razones, entre las que destacaré: la fragmentación religiosa contemporánea paralela a la crisis de las iglesias hegemónicas e institucionalizadas, proceso que en España se acelera después de la transición democrática; el carácter pasi-

\footnotetext{
${ }^{2}$ Son todos apelativos equivalentes y aluden a la congregación de hermanos que se reúne en un local para orar, cantar, alabar, compartir creencias e inventar juntos, en definitiva, una nueva manera de representarse el mundo.

${ }^{3}$ Los líderes eran al principio todos misioneros franceses, pero esto ha cambiado y en la actualidad tanto el presidente del Consejo de Dirección como los líderes regionales (o "responsables de zona") son, en su mayoría, gitanos españoles.
} 
vo del papel que la Iglesia Católica ha reservado tradicionalmente a los gitanos; los profundos procesos de cambio que están experimentando todos los sectores del mundo gitano a causa de la creciente incorporación a los núcleos urbanos, la reubicación urbana de las familias por parte de las administraciones autonómicas y la consiguiente mezcla de linajes diferentes y, a veces, enfrentados; los cambios económicos y ocupacionales que han abierto fracturas difíciles de suturar; la creciente fuerza del fenómeno asociativo gitano, paralelo en el tiempo a la emergencia de las iglesias gitanas; los graves problemas derivados de la incorporación de muchos gitanos jóvenes a las redes de venta y consumo ilegal de drogas intravenosas; y el prestigio en aumento del mismo movimiento evangélico, en constante expansión. Pero, sobre todas estas razones, yo destacaría una que, por evidente, tiende a pasar desapercibida: el liderazgo gitano de las congregaciones que, por un lado, refuerza la dimensión étnica de las nuevas iglesias y, por el otro, impregna toda una dinámica congregacional que no entra en contradicción con el modo de vida gitano, sino que se suma sin demasiados conflictos a él. El pastor es un gitano que cambia con frecuencia de iglesia ${ }^{4}$ y cuya actividad económica principal es, como la de la mayoría de los miembros de la congregación que lidera, la venta ambulante de "género" diverso. Tiene familia e hijos, ha de mantenerlos. Y además se ocupa diariamente de su congregación, ya que los cultos suelen celebrarse seis días a la semana.

Tal vez el pentecostalismo gitano no sea sino una manifestación más de un movimiento de amplio alcance que ya ha ganado terreno en sociedades de larga hegemonía católica, como es el caso de casi toda América Latina, para el que se han explorado desde hace tres décadas las razones de un éxito considerado espectacular (Cantón 1998). Son razones bien conocidas:

\footnotetext{
${ }^{4}$ Los pastores gitanos son instados a cambiar de congregación cada dos o tres años, a veces cada pocos meses. Ello se debe, principalmente, a la fatiga que provoca la celebración diaria de cultos y reuniones. Como nos narraba un pastor del Campo de Gibraltar (Cádiz): "la dedicación es total y la relación con la gente es continua, estamos muy en contacto con sus problemas, conseguimos en dos años lo que en otras iglesias se consigue en seis". Un obrero sevillano me comentaba en este mismo sentido: "La función del pastor es muy dura, son seis cultos a la semana, hay reuniones después del culto, en casas particulares, muchas noches, y además vigilias, bodas, presentaciones de niños... llega un momento en el que el pastor está muy cansado y pide razonadamente que le releven del cargo y se busque otro pastor que pueda hacerse responsable de la congregación que deja". Esta dinámica de cambio constante de pastor dificulta, asimismo, que un pastor se haga fuerte en una congregación y caiga en la tentación (muy frecuente en el pentecostalismo, dada la autonomía de las iglesias locales) de crear su propia corriente disidente. Por último, es algo que conecta con la movilidad típicamente gitana y no entra en contradicción con la actividad económica predominante: la venta ambulante.
} 
la ductilidad del pentecostalismo, su sencillez doctrinal, la descentralización organizativa y la autonomía de las iglesias locales, el carácter participativo de los cultos, la flexibilidad del sistema de liderazgo, la estrategia de la diferenciación celular, la fuerza de su proyecto evangelizador y sus acciones proselitistas, el empuje del milenarismo que defienden y, sobre todo, la adaptación a contextos culturales muy dispares. Estas son razones de alcance general, pero el movimiento evangélico gitano en Andalucía no puede desvincularse de los procesos de cambio específicos que afectan al aún mayoritario catolicismo, a la sociedad no gitana dominante y, sobre todo, a las transformaciones que han experimentado los gitanos en sus tradiciones y modos de vida.

Hagamos ahora un brevísimo repaso histórico e introduzcamos algunas cifras, antes de pasar a enfocar una congregación evangélica muy especial emplazada en el Polígono Sur sevillano. Las iglesias Filadelfia ${ }^{5}$ gitanas representan el lado más visible de un movimiento de carácter étnico-religioso de impacto y dimensiones sin precedente histórico en el mundo gitano. Se trata de un sistema de creencias religiosas que, en la forma que hoy encontramos entre los gitanos, tiene su origen en Francia. Fue en Brest (Normandía), donde un pastor no gitano de la Asamblea de Dios comenzó a predicar entre los gitanos que trabajaban como temporeros en las labores propias de la vendimia. Clement Le $\operatorname{Cossec}^{6}$ encontró entre los trabajadores desplazados muchos gitanos españoles, quienes, a su vuelta, comenzaron a extender la nueva doctrina entre los suyos. En Brest se bautizaron por inmersión los primeros gitanos convertidos al pentecostalismo por obra de Le Cossec (Jordán 1990: 9-10).

En 1965 llegaron siete predicadores gitanos de Francia, y entre ellos y Claudio Salazar - apodado "Palko", también payo y francés- fundaron la Iglesia de Filadelfia en España ${ }^{7}$. El evangelismo empezó así a extenderse entre

${ }^{5}$ Filadelfia es el nombre de una denominación pentecostal que evoca la ciudad de Lidia, fundada por Atalo Filadelfo en el monte Tmolus (Asia Menor). El nombre actual de la antigua Filadelfia es Ala Sheler, una ciudad que se encuentra en Turquía. Filadelfia fue una de las siete iglesias de Asia a las que el apóstol Juan dirigió sus cartas. Estas iglesias eran: Éfeso, Esmirna, Pérgamo, Tiatira, Sardis, Laodicea y Filadelfia ( $A p$. 1:11; 3:7-13)

${ }^{6}$ Le Cossec decidió, a partir de las primeras conversiones de gitanos, transformar las antiguas Asambleas y fundar la Misión Evangélica Gitana, ofreciendo la posibilidad a los mismos gitanos de convertirse en pastores de su pueblo. Eso ocurrió en 1957. A partir de ese año y durante los sesenta y setenta, la obra se extendió rápidamente por Francia y los estados adyacentes, y Le Cossec - fallecido en 2001- quedó desde entonces como líder reconocido de toda la obra evangélica mundial entre los gitanos.

${ }^{7}$ En 1969 el Gobierno español admitió finalmente la inscripción bajo el nombre de "Iglesia Evangélica de Filadelfia", tras rechazar el de "Misión Gitana", por considerar 
los gitanos catalanes. Los cincuenta fueron unos años difíciles, años oscuros del franquismo, del hambre, de la represión política y social. Jiménez narra con detalle la persecución sufrida en aquellos inicios, lo que en las páginas que siguen veremos refrendado en las palabras de Nicolás Pisa, uno de nuestros principales informantes y un gitano que me ha prestado su voz para componer la historia del próximo apartado. Jiménez nos habla de la falta de libertad religiosa, de la intolerancia, del "rechazo de los gitanos incrédulos", del hambre y la pobreza de aquellos años, de la penuria de medios con la que se desplazaban en esos primeros tiempos de expansión frenética, de constante evangelización y apertura incansable de nuevos cultos, uno tras otro: "Muchos decían '¿desde cuándo los gitanos hablan y se han vuelto curas?" o "los gitanos de Valladolid nos llamaban curas" (Jiménez 1981: 29 y 48). En los años sesenta dos gitanos franceses (Lari y Joselito) recibieron el "llamado de Dios" para predicar en el sur de España y fue así como llegaron a Sevilla en 1968.

Aunque las congregaciones gitanas andaluzas no están excesivamente organizadas en el plano eclesial ${ }^{8}$, no cabe duda de que la improvisación de los primeros tiempos está dando paso a un mayor deseo de controlar y supervisar la marcha de la obra a nivel local, regional y nacional. Los registros de la membrecía son en general muy rudimentarios, y en algunos casos sencillamente no existen. Pero podemos aportar algunos datos. Andalucía es, tras

que "en España los gitanos eran españoles" (Jiménez 1981: 91). En este año y los siguientes se produjeron conversiones multitudinarias en Barcelona, Balaguer, Madrid, Santander, Tarragona, Castellón, Mallorca, Teruel, Huesca, Valladolid, Zaragoza y Burgos. "Palko" regresó a Francia en 1979 y se desvinculó del movimiento gitano, pero hasta ese año fue el Secretario General de la Obra Gitana en España. En 1968 había convocado las primeras reuniones evangélicas en Balaguer (Lérida), donde se fundó la primera Iglesia Filadelfia en España. Cinco de aquellos siete misioneros llegados de Francia se repartieron por Cataluña y Castilla, mientras los predicadores Lari y Joselito bajaron hasta Sevilla en 1968.

${ }^{8}$ El rechazo a una organización jerárquica compleja es, no obstante, común a todo el pentecostalismo y a muchas religiones emergentes. Sus seguidores estiman que la institucionalización y la burocracia son las responsables del anquilosamiento, la pérdida de vitalidad y la crisis generalizada que experimentan las iglesias tradicionales (también las del llamado "protestantismo histórico"). De hecho las comunidades locales gozan de una relativa independencia. Eso sí, en el caso de las iglesias gitanas cada pastor debe obediencia al "responsable de zona", por encima del cual sólo se encuentra el Consejo de Dirección de la Iglesia Filadelfia (Consejo Nacional). Anualmente, pastores y predicadores con más de cuatro años de ministerio votan para elegir a un líder nacional, que se constituye en Presidente del Consejo, y a los diferentes líderes regionales o "responsables de zona". Todos ellos forman el Consejo Nacional. La organización jerárquica está compuesta, pues, por el responsable nacional, los responsables de zona y los pastores de las iglesias. 
la comunidad valenciana, la autonomía con mayor número de iglesias y de conversos gitanos. La "zona" de Andalucía Occidental ("Andalucía la vieja") se mantiene aglutinando las provincias de Sevilla, Cádiz, Málaga y Huelva; mientras la antigua "zona" de Andalucía Oriental se ha dividido en dos: Jaén y Córdoba por un lado, Granada y Almería por el otro. Los últimos datos fidedignos con los que contamos corresponden al año 1998, en el que Andalucía Oriental (las antiguas cuatro provincias) contaba con 45 iglesias, entre 3.900 y 4.000 fieles, y 131 pastores y obreros; para Andalucía Occidental las cifras eran de 46 iglesias, entre 6.000 y 6.500 fieles y 95 pastores y obreros (Cantón 1999: 190 y ss.). Según el número de iglesias con las que cuentan, las provincias seguirían este orden: Jaén, Cádiz, Málaga, Granada, Sevilla, Almería, Córdoba y Huelva. Todo ello sin contar los "puntos blancos" (lugares de predicación sin culto regular) que se abren y cierran constantemente. Además, habría que añadir los cinco centros de desintoxicación de drogodependientes vinculados a las iglesias (Marcos 1999: 135-140), y localizados en Almuñécar (Málaga), La Línea de la Concepción, Jerez de la Frontera, Algeciras y Sanlúcar de Barrameda (estos cuatro en Cádiz).

Nuestro trabajo de investigación se ha centrado en la Baja Andalucía, es decir, las provincias de Cádiz y Sevilla9. Entre las congregaciones de Sevilla capital destaca una, la más antigua, que actualmente cuenta con unos 200 miembros, mayoritariamente gitanos. La iglesia del Polígono Sur se ubica en un barrio obrero construido en la década de 1970 y conocido popularmente como Las Tres Mil Viviendas. Se trata del barrio más poblado de todo el Distrito Sur sevillano: de hecho cuenta con más de 20.000 habitantes, de los cuales unos 8000 son gitanos. De ahí que podamos afirmar que este barrio concentra la mayor cantidad de familias gitanas de la ciudad de Sevilla. El desempleo de los años setenta y ochenta impactó gravemente en el barrio favoreciendo la aparición progresiva de bolsas de pobreza y, en consecuencia, de marginalidad, droga, delincuencia e inseguridad. Muchos se marcharon entonces tras vender ilegalmente sus viviendas, que eran en realidad de titularidad pública (propiedad del Estado). Esto favoreció la aparición de un mercado ilegal de la vivienda que, en barriadas extremas como las conocidas por el sobrenombre de Las Vegas, han aprovechado traficantes que se han hecho con pisos a bajo precio en los que venden su mercancía (drogas, objetos robados, etc.). El entorno se ha ido volviendo inhabitable, se han generado nuevas formas de infravivienda, y los problemas de exclusión se han agudizado hasta volverse lacras de difícil solución.

\footnotetext{
${ }^{9}$ Se trata de un trabajo en equipo que coordina la autora de este artículo y en el que se investigan tres licenciados en Antropología Social que realizan sus tesis doctorales sobre el tema: Cristina Marcos (1999), Salvador Medina (1999) e Ignacio Mena (1999). La investigación ha sido financiada, en dos campañas consecutivas (1999-2000 y 2001-2002), por la Consejería de Cultura de la Junta de Andalucía.
} 
Pues bien, la Iglesia Evangélica Filadelfia del Polígono Sur, conocida entre los gitanos como "La Iglesia de Sevilla", es la heredera del primer grupo de conversos que se forma en torno a los predicadores franceses Lari y Joselito, llegados a Sevilla en los años sesenta. Se trata de una iglesia emblemática del evangelismo gitano andaluz. De allí nos llegan estas dos voces gitanas.

\section{MEMORIAS GITANAS: LA LLEGADA DE LOS FRANCESES EN LOS AÑOS SESENTA}

Vamos a entrecruzar dos relatos: el de Nicolás Pisa, hijo del Tío Bejerano, en cuya casa del Polígono de San Pablo (Sevilla) se realizaron los primeros cultos evangélicos de toda Andalucía; y el de la madre de Nicolás y viuda del Tío Bejerano, la Tía Rosario. Lo que sigue es una composición realizada a partir de varias entrevistas realizadas a Nicolás y Rosario, dos personajes claves para articular la memoria gitana de aquellas primeras conversiones ${ }^{10}$.

\section{Nicolás Pisa}

Todo empieza aquí en Sevilla, en el Polígono de San Pablo, cuando llega Joselito a mi casa. Eso fue en el año 1968. Yo estaba con mi padre, que era un gitano que recibía muy bien. Todos los días hacía dos braseros ${ }^{11}$ y dos ollas grandes de café, uno para la familia, otro para el que llegaba. Mi padre nació en Valladolid, era un gitano de metro ochenta, con sombrero de ala ancha, traje cruzado, zapatos de dos colores (Nicolás habla con orgullo). Los gitanos van y vienen con las ferias, así que de Valladolid se fue a Madrid, donde conoció a una muchacha muy guapa, mi madre, y se casaron... pero antes, cuando estaban pedidos, de novios, a mi padre lo llevaron de prisionero de guerra... era el año 1939, eso me contó él. Entraron las tropas de los nacionales en Madrid y sospechaban de todo el mundo, así que se lo llevaron de San Sebastián a Bilbao, construyendo puentes, picando las mon-

\footnotetext{
${ }^{10}$ La narración recoge textualmente la voz de los entrevistados, sólo han sido suprimidos los momentos vacilantes y algunos fragmentos irrelevantes para lo que queríamos mostrar. Este apartado es un ensayo de "historia polifónica" (Pujadas 1992) y su presentación en estas páginas no tiene un carácter meramente literario, sentimental u ornamental: la información que se desprende de las palabras de Nicolás Pisa y la Tía Rosario ha sido triangulada, es decir, contrastada con otros muchos testimonios que nos hablan de aquellos orígenes del evangelismo gitano andaluz para los que apenas contamos con información escrita.

${ }^{11}$ El "brasero" es el nombre que recibe el sistema tradicional de calefacción a base de carbón colocado en un platillo sobre el suelo, y cubierto con una rejilla que protege de las brasas a quienes se encuentran cerca.
} 
tañas, pero cuando vieron que era gitano y que entendía de bestias, le acabaron encomendando que cuidara de las yeguas y así fue como poco a poco se libró de aquello. Como en realidad no tenían nada contra él, un día lo dejaron libre, así que vuelve a Madrid, se casa y nace mi hermano Pepe $^{12}$. Con las ferias nos tuvimos que venir a Sevilla, a Triana en un principio, luego a varias chabolas.... estábamos muy mal, con frío, con hambre, con mucha necesidad. En el año 1961 hubo una gran riada, se inundaron las chabolas, y nos tuvimos que trasladar porque la chabola se vino abajo, nos llevaron a un refugio y luego, escoltados por la Guardia Civil, nos expulsaron de Sevi1la. A mi padre le dijeron que tenía que meternos a todos sus hijos en un correccional, por las condiciones en las que vivíamos, y él se negó. Así que nos echaron a todos de Sevilla y nos dieron billetes de tren para Jerez. Allí estuvimos un par de meses y luego volvimos a Sevilla, a los barracones de Torreblanca ${ }^{13}$, donde estuvimos poco tiempo, para de allí irnos al Polígono de San Pablo.

Estando nosotros allí, en el Polígono de San Pablo, llegó Joselito en un Peugeot 504, de color blanco, es como si lo estuviese viendo ahora... y mi padre dijo: "¿Qué hace ese gitano en un coche tan lujoso?", entonces Joselito se bajó y saludó, y dijo "vengo a hablarle como gitano de la palabra de Dios", y mi padre llamó a mi madre y le dijo: "venga, échale un café a este gitano!" Decía que había orado a Dios para que le condujera al lugar exacto en el que podría encontrar a los gitanos de Sevilla, y así fue como primero se encontró con Pedro el gitano, que vivía en la calle junto a la nuestra. En casa del Tío Pedro empezaron las primeras reuniones, allá por el 1969, pero sólo fueron cuatro o cinco reuniones. Poco después empezaron a hacerse ya en mi casa, donde se estableció la iglesia y se hizo fijo el grupo de predicación, en mi casa se pasaba la ofrenda y se tomaba el pacto. En mi casa hubo iglesia unos dos años, y al final ya nos reuníamos 40 o 50 gitanos allí... recuerdo que ya no cabíamos, había gente hasta la puerta, que no se podía cerrar ni abrir, allí de pie, y los más jóvenes por el suelo. El culto lo daban los franceses Lari y Joselito, que pasaban largas temporadas aquí. Luego vi-

${ }^{12}$ Se refiere a Pepe Pisa, el mayor de los hermanos Pisa, hijo de la Tía Rosario y el Tío Bejerano. Todos ellos pertenecen a la extensa familia de Los Madrileños, llegados de Madrid en los años sesenta. Pepe Pisa es un personaje histórico en el evangelismo gitano español y andaluz, y ha sido durante muchos años pastor y "responsable de zona" para toda Andalucía Occidental. A su labor se debe la mayoría de las iglesias fundadas en esta parte de Andalucía (Málaga, Sevilla, Cádiz, Huelva), y también la primera evangelización de Andalucía Oriental, concretamente entre los gitanos de Granada.

${ }^{13}$ Torreblanca es un distrito muy poblado, situado al este de Sevilla, donde reside un gran número de gitanos. Tradicionalmente, la mayoría se alojaba precariamente en un extremo del barrio conocido como "los barracones". 
nieron los primeros bautizos que se hicieron en Andalucía: mi hermano Pepe Pisa y su mujer, mis padres el Tío Bejerano y mi madre Rosario, y José Serrano y su mujer. Todos se bautizaron en la piscina que Carlos el suizo tenía en el barrio de Santa Clara, que le llamaban el barrio de los americanos. El suizo era un pastor payo que nos ayudó mucho, allí se instalaba el carromato (roulotte) de Lari y Joselito cuando estaban en Sevilla, y él les daba agua y luz de su propio chalé. José Serrano fue el primer pastor que salió aquí en Sevilla. Eran tiempos muy duros... nos ibamos a ayunar a los olivos, pero había mucha hambre; uno de los que íbamos se guardaba un bocadillo dentro de la chaqueta, y no veas la que se armó cuando lo descubrieron, porque decían "Nosotros aquí ayunando y éste escondiendo un bocadillo ipor eso el Señor no nos bendecía!" (ríe)... eran otros tiempos, había mucha hambre, mucha miseria y mucha ignorancia.

Recuerdo a Lari el francés, era muy alto, casi dos metros, con larga melena, rizos rubios como Jesucristo... Era como un armario, muy fuerte. Un día en que estábamos reunidos vino un guardia civil, porque estábamos muy vigilados en el franquismo, y Lari le dijo "tienes suerte de que estoy convertido, anda y déjanos en paz que aquí sólo estamos hablando de la Palabra"... Y es que no nos dejaban ni reunirnos, aunque ya en los setenta la cosa iba cambiando y al menos veinte nos podíamos reunir sin que sospecharan. De Lari recuerdo que tenía tres predicaciones nada más (ríe), empezaba con la primera, parece que lo estoy viendo ahora... empezaba con la primera, lo hacía muy bien, días más tarde le oías la segunda, luego la tercera y vuelta a empezar con la primera (ríe), y es que en aquellos tiempos no conocían bien la Biblia. Fíjate que Pepe Pisa se bautizó y al día siguiente ya estaba predicando, entonces ni se exigía que antes llevaran una etapa como candidatos ni nada, eran otros tiempos, había mucha necesidad, mucho que hacer y muy poca preparación.

\section{Rosario}

Aquí en Sevilla predicaban los franceses Lari y Joselito, y luego José Serrano, porque fijate que mi hijo Pepe no quería al principio saber nada de la iglesia... estuvo como dos años sin querer saber nada, hasta que se le puso un niño muy malito, con dos o tres meses, con meningitis, muy grave. Lari el francés se puso a orar por el niño y Pepe dijo que pondría una condición: le dijo al Señor "si me curas a mi hijo, me entrego a ti". Pero el niñito murió. Lari seguía diciéndole "tú tienes que ser el predicador que salga de aquí, de Sevilla, para evangelizar Andalucía". Entonces Pepe, al morir su hijo, le volvió a pedir una señal al Señor: "si es verdad lo que dice Lari, que tú quieres que sea para ti, mándame una señal". Tuvo una niña que era sorda y casi 
muda, y un día Pepe pudo oír cómo la niña le decía "papá, agua", y vio una luz como de una vela en los pies de la cama de la niña, una vela que ni se apagaba ni crecía. Entonces mi hijo Pepe dijo, "Señor, esto quiere decir que me quieres para ti, entonces me entrego". Al mes, cuando Lari volvió, mi hijo al fin se bautizó.

\section{Nicolás Pisa}

En aquella época los gitanos del barrio, que eran muchos, nos llamaban locos. Se mofaban de nosotros, se reían al vernos pasar, pero nada fuerte, porque el gitano a las cosas de Dios siempre les ha tenido respeto. $\mathrm{Y}$ así fue creciendo aquella primera iglesia, porque ten en cuenta que evangelismo y pueblo gitano tienen mucho que ver... al principio acuden varios de la familia, y luego acude todo el clan... por eso yo no sé si el evangelio es capaz de unificarnos a los gitanos, porque el ochenta por ciento de una iglesia pertenece seguramente al mismo clan... Claro que ahora a lo mejor es un poco diferente, pero en aquella época evangelismo y clan tenían mucho que ver, porque había más desconfianza que ahora, y el culto crecía gracias al clan. Ahora los jóvenes ya ven el culto como algo normal, algo estable, pero entonces había que empezar por una familia y esperar a que se sumara el resto del clan, y había que implicarlos a todos... tal hijo lleva la ofrenda, y así él tiene esa responsabilidad, el hijo mayor del patriarca ${ }^{14}$ es el que se hace pastor... y así iba involucrándose todo el clan, porque no había otra manera de crecer.

Pero sí, nos llamaban locos... ten en cuenta que lès recordábamos a los curas, y que el cura era el payo, el gachó al que había que pedirle o mangarle (robarle), ya sabes, todo aquello del gitanismo pobre, lo típico de la comunidad gitana, sin acceso a la cultura ni a la información desde siempre ${ }^{15} \ldots$ Nosotros asistíamos a misa porque era el precio que teníamos que pagar por la leche en polvo o por el trozo de queso, pero nada más.

14 "Patriarca" es la palabra no gitana para designar a la figura de respeto que los gitanos llaman "Tío".

15 Nicolás Pisa, al igual que varios de su familia, llevan la Asociación gitana Villela Or Gao Caló (Viene el Pueblo Gitano), desde la que se intenta promover la educación de los jóvenes gitanos y que forma, junto con otras asociaciones, una de las plataformas de reivindicación ciudadana más importantes en uno de los sectores urbanos más pobres, abandonados e inseguros de toda Sevilla: el Polígono Sur. 


\section{Rosario}

Yo a lo primero no quería saber nada, pensaba "ipero es que están locos estos dos estudiantes ${ }^{16}$, se han vuelto locos de tanto estudiar!" (ríe)... Y les decía "estáis locos, ¡dejadnos en paz!". No quería saber nada hasta que me curaron a una hija con reuma, que tenía los pies retorcidos y los médicos decían que no tenía cura. Desde ese momento me entregué al Señor. Mi marido, el Tío Bejerano, se convirtió antes. A él le dijeron los franceses, "si tu quieres conocer al Señor, cuando te quedes sólo en tu habitación, órale para que te escuche". Lo hizo, y salió diciendo a gritos "iqué gozo, qué alegría, nunca había sentido algo así!"... Pero sin embargo yo no quería saber nada, yo decía "ipero si yo no he echado maldiciones, ni he jurado a mis niños, yo soy buena, tengo un duro ahorrado y lo doy a la que lo necesita, en lugar de comprarme un corte nuevo (un vestido), ipara qué le voy yo a hacer caso a estos locos?". Pero le oré al Señor y lo sentí en mi corazón, y sobre todo cuando me curó a mi niña le entregué mi vida ${ }^{17}$, y ahora digo lo mismo que el corito que le hacemos al Señor, porque hay un canto nuestro que dice: "bendita locura que tienen los aleluyas".

\section{Nicolás Pisa}

Como el cura era el payo y el pastor era una especie de cura, pues los gitanos no entendían y nos llamaban locos... lo que pasaba es que nunca habíamos escuchado el tipo de mensaje que traía aquel gitano francés, y así nosotros mismos habíamos pensado que estaban locos, pero los escuchamos como gitanos que eran, los recibimos porque eran gitanos, les dimos café y los escuchamos... pero, en verdad, también pensábamos que estaban locos. Claro que al mismo tiempo era algo nuevo, algo que nunca habíamos escuchado antes, de un Cristo que había muerto por nosotros y que nos amaba, ja nosotros los gitanos!, y luego esa elocuencia... el mensaje que traían aquellos gitanos franceses no era el del Padrenuestro, ni le rezábamos a la Virgen María, lo de siempre de los católicos... no. Aquello era otra cosa. Era un

16 "Gitanos estudiantes" resulta una combinación extraña para esa época. Rosario no sabe explicarme por qué los asoció con estudiantes, pero de sus palabras deduzco que tal vez fue porque "hablaban demasiado", daban lecciones, "sabían mucho" y lo contaban con mucha convicción... todo lo cual es, para Rosario, propio de "gente que estudia".

${ }^{17}$ En otro lugar me he ocupado extensamente de las relaciones entre curación y creencia religiosa que, como vemos tanto en el caso de Pepe Pisa como en el de su madre, la Tía Rosario, son claves para entender los procesos de conversión (Cantón 1996). 
mensaje fabricado de corazón a corazón, de pobre a pobre, de gitano a gitano. El mensaje es el mismo que se dan los payos entre sí, el mensaje es de Dios, el mensajero es el que cambia... ¿debo o no recibirte, me fío o no me fío de ti, te permito o no dormir en mi casa, bajo mi mismo techo? Esa es la cuestión. Para eso hay que ser gitano, y aquellos locos franceses lo eran. Por eso les dimos café aquella tarde y los escuchamos... y hasta hoy.

\section{TEJIENDO IDENTIDADES: CREENCIAS PROTESTANTES, ESTRATEGIAS GITANAS}

En Andalucía, y concretamente entre los grupos gitanos que hemos conocido, vemos que el pentecostalismo sigue caminos paradójicos para filtrarse en la cultura gitana, y viceversa. Por un lado, el movimiento evangélico gitano promueve la reafirmación en la propia identidad cultural, el reforzamiento de los lazos de solidaridad, que ahora se extienden más allá de los linajes alcanzando a la comunidad religiosa de hermanos en la fe; es el reconocimiento como un pueblo distintivo, el pueblo gitano, "elegido por Dios como lo fueron los judíos"; es decir, por un lado los nuevos vínculos (fundados en muchos casos sobre los viejos vínculos) permiten hacer frente a la disgregación y el individualismo modernos a los que parece abocarlos la desmembración de sus tradiciones y su cultura. Pero por otro lado, las iglesias brindan un espacio para la renovación y la creatividad cultural, y el mismo acceso a ellas ocurre de una manera que es postmoderna y es gitana, es individual, libre y, al mismo tiempo, está gobernada por la lógica familiar, la lógica del clan. Como explica Hervieu-Léger, el renacimiento de las comunidades religiosas de todo tipo en el mundo contemporáneo debe ser entendido como una dimensión de la modernidad religiosa y del moderno individualismo. Y ello porque, primero, esas comunidades permiten forjar nuevas identidades a través de una red de grupos de afinidad voluntaria (más allá de los grupos primarios de referencia que son el eje sobre el que se organiza la vida pre-moderna); segundo, porque se ofrece la posibilidad de la experiencia personal; tercero, porque se facilitan los medios para construir la propia identidad individual a través de la experiencia religiosa y el testimonio personal (Hervieu-Léger 1993: 95).

El evangelismo gitano está permitiendo intensificar un proceso de reafirmación de la identidad cultural de los gitanos, pero esto ocurre de una manera que combina los antiguos modos de entender la cultura propia y las relaciones socio-familiares, con nuevas maneras de ejercer el liderazgo y entender el papel de sectores como las mujeres y los jóvenes gitanos en un mundo marcado por la distorsión extrema de las tradiciones. Es decir, la Iglesia de Filadelfia está acelerando los procesos de cambio dentro de un marco 
de reconocimiento a los valores centrales de la cultura gitana, no de rechazo o abandono. La renovación viene de la relectura crítica que se realiza en las iglesias de las costumbres y tradiciones gitanas: desde los templos se ponen en marcha formas distintas de entender las identidades gitanas revisándose, por ejemplo, el papel de las mujeres y los jóvenes, o la violencia prevista en la ley gitana para enfrentar las conductas consideradas ofensivas (la agresión física que puede conducir al asesinato, la venganza, el destierro para evitar males mayores, etc.), así como las relaciones con los vecinos no gitanos, la necesidad de respetar "su ley" y evitar las estafas, los robos, la transgresión penalizada desde el sistema jurídico payo. El gitano evangélico no quiere dejar de ser gitano, no ha interiorizado hasta ese extremo el estigma que pesa sobre su cultura, ni utiliza la religión para desvincularse de la lógica comunitaria que ya ha dejado de resultarle ventajosa, como de hecho ocurre en numerosas poblaciones indígenas centroamericanas que he conocido (Cantón 1998). Esa relectura crítica de las tradiciones y las identidades gitanas que se realiza en el seno de las nuevas agrupaciones religiosas está, asimismo, acompañada de una intensa toma de conciencia de la desgracia histórica, de la marginación y el abandono, y de una suerte de amargo convencimiento acerca de la imposibilidad de encontrar salidas fuera del propio mundo gitano.

En este sentido, la identificación de los gitanos evangélicos con el pueblo judío en tanto que pueblo "perseguido" y "elegido" por Dios, es una constante en los discursos. Adolfo Jiménez, un histórico del evangelismo gitano en España, lo explica de este modo: "Hemos servido de refrán y burla, hemos padecido las mismas iniquidades que ellos, y hemos sido esparcidos por las naciones, como ellos". Y prosigue, hasta llegar a definir el evangelismo como si se tratara de la Tierra Prometida de los gitanos: "Ya no somos un pueblo sin esperanza ni rumbo; ahora tenemos un futuro [...] Ahora ya tenemos patria y la promesa de una morada fija”. La morada, la patria es, en este caso, la creencia pentecostal pan-gitana, y no un Estado como en el caso israelí. De hecho, el papel desempeñado por Moisés como guía de los israelitas fue, según Jiménez, el mismo que más tarde jugaría Le Cossec, "un fervoroso anciano, no gitano", para sacar a los gitanos "de la ruina y el pecado". Un Moisés para los gitanos en pleno siglo XX (Jiménez 1981: 17-18; 23).

Centrémonos un momento en las iniciativas más renovadoras y creativas que están promoviendo los gitanos evangélicos. Con respecto a las mujeres gitanas y las relaciones de género, la mejoría más visible viene del cambio de actitud con respecto a la violencia que los varones se estiman legitimados para ejercer sobre ellas, que así se ven beneficiadas con un trato éticamente más acorde con una religión que proscribe la violencia y promueve el entendimiento pacífico a través de la palabra. Por su parte, los sectores más jóvenes del evangelismo gitano, la tercera generación ya de 
pastores, están propiciando cambios drásticos que tienen que ver con la inclinación a facilitar que las mujeres adquieran formación para poder compartir las tareas de evangelización con los hombres. Esta labor se imbrica con la que llevan a cabo muchas asociaciones gitanas, y con una necesidad evidente de facilitar el acceso a la educación formal a todos los niveles para los jóvenes gitanos, lo que es muy valorado desde las iglesias. Aprender a leer y escribir ya no es útil solamente para poder obtener el permiso de conducir, como señala Wang, sino también porque ello les permite poder interpretar la Biblia y, de esta manera, acceder al grado de pastor. Los beneficios, es obvio, van mucho más allá de esta aspiración (Wang 1989: 430).

Más creatividad sobre los viejos modos: el pentecostalismo gitano prospera, en buena medida, gracias a las redes de parentesco que permiten la conversión de familias enteras. Nicolás Pisa nos habló de ello y así ha quedado recogido páginas atrás. La estructura familiar y de parentesco, principio organizador de la vida política, económica, social y simbólica entre los gitanos, es una de las más importantes vías de entrada del evangelismo. Los pastores lo saben y no suelen dar un paso sin contar con los patriarcas de los clanes. Naturalmente, no faltan los casos en los que las familias gitanas están resintiéndose por la conversión de algunos de sus miembros y la aceptación, a partir del momento de la conversión, de un código de conducta que, al rechazar la violencia, conculca la ley gitana y deja sin vengar los agravios. Pero en general nos encontramos con una modalidad de evangelismo no rupturista, un evangelismo negociador con la cultura gitana ${ }^{18}$, más bien indiferente ante un catolicismo (aún dominante) que no combaten con la beligerancia de las iglesias evangélicas no gitanas, y nítidamente separado de éstas últimas, aunque sin mostrar hostilidad hacia ellas. Muy probablemente porque las adscripciones religiosas entre los gitanos siempre han tenido un carácter subsidiario con respecto a la filiación étnica, y esto no es diferente entre los pentecostales.

El culto está contribuyendo, lenta pero tal vez decisivamente, a enfrentar de otra manera, desde dentro, con armas propias, los problemas de exclusión social, política y económica, y de estigmatización cultural, que han

\footnotetext{
${ }^{18}$ Hay casos de gitanos inconversos que acuden a los pastores evangélicos para que medien en un conflicto como personas con autoridad reconocida, para que "presenten" a su recién nacido e incluso para que celebren una boda (a lo que los pastores se niegan sin excepción), ya que confían más en uno de los suyos, un gitano, aunque sea evangélico, que en un sacerdote católico no gitano. En la otra dirección: muchos pastores gitanos afirman actuar en el mundo gitano "como gitanos", y no tanto como evangélicos: un pastor sevillano afirma "si medio en un conflicto entre gitanos que no son evangélicos y que se han peleado, no les hablo de poner la otra mejilla como dice la Biblia, sino del destierro para evitar la venganza de la familia ofendida".
} 
afectado históricamente y continúan afectando de manera dramática a amplios sectores del mundo gitano (Gamella 1996). Y eso en la Baja Andalucía, que cuenta con una de las más largas historia de asentamiento y sedentarización de la población gitana y uno de los procesos de mezcla e integración más claros del mundo. El caso de Jerez de la Frontera es paradigmático, y de hecho sus dos iglesias evangélicas gitanas son mixtas desde el punto de vista étnico: los gitanos y los payos están mezclados casi en igual proporción. En el caso de la exclusión económica y la actividad mayoritaria entre los gitanos evangélicos - la venta ambulante- hay consideraciones muy interesantes que podemos hacer, aunque no desarrollar en el espacio de estas páginas: nos referimos a la reorientación de los comportamientos económicos entre los conversos, los cambios de actitudes ante las actividades económicas, el posible impacto de una nueva "ética protestante" del trabajo entre los gitanos evangélicos, la mejora modesta de la situación económica de las familias y la consiguiente movilidad social (también modesta).

Pensemos que, por lo común, los estudios sobre nuevas religiones conversionistas presentan las carencias socioeconómicas como determinantes del auge de las conversiones a religiones emergentes, mientras se minimizan e incluso ignoran las transformaciones derivadas de las nuevas creencias, como es el caso de la aceptación de una ética del trabajo distintiva. Esto forma parte de una actitud más amplia de ceguera académica ante los cambios originados en los procesos creativos de apropiación estratégica que siguen a las conversiones religiosas (Cantón 2001: 236-237). Y aunque es cierto que los pentecostales suelen apostar por la reforma moral y no tanto por el éxito material, sin embargo también es verdad que promueven la honestidad en el trabajo, la evitación del despilfarro, un cierto ascetismo que limita el disfrute al contexto de las celebraciones de la iglesia, la prohibición expresa del gasto en alcohol, tabaco, juego y otras actividades consideradas "viciosas", muy especialmente en ese terreno minado que es el consumo y venta ilegal de drogas intravenosas, gravísimo problema convertido en punta de lanza de la obra social de las iglesias gitanas. Esto tiene efectos sobre las economías domésticas en la medida en que se estimula una inversión más "racional" del presupuesto familiar. Los ideales del trabajo productivo y racional, de movilidad social, de prosperidad material, no están ausentes de las comunidades pentecostales en general. Es una versión de estos ideales, lógicamente adaptada a los contextos y comportamientos gitanos, lo que encontramos en las iglesias de Filadelfia que hemos estudiado.

Es posible entender las prácticas religiosas gitanas como más devotas que dogmáticas en tanto se trata de una devoción atravesada de reivindicaciones extraconfesionales que redefinen las identidades y atañen a la organización política, económica y familiar gitana. Parece claro que esos "lugares de lo 
religioso" se revelan lugares sociales y políticos, lugares de cambio y permanencia, y lugares del intercambio económico. El entusiasmo por la nueva religión evangélica reapropiada en clave étnica no se debe sólo a la lucha contra la adicción a las drogas intravenosas (heroína principalmente) y, sin duda, está lejos de obstaculizar el consenso entre los gitanos o de constituir una línea de fractura que impida la unidad gitana. Más bien al contrario. Pensemos que, por vez primera, un importante número de gitanos respeta una autoridad centralizada: el Consejo Nacional de la Iglesia Filadelfia, con sede en Madrid, formado por un Presidente, un secretario y los "responsables de zona" de toda España (tres de ellos son andaluces). Y, más importante aún: pensemos que hasta ahora las obligaciones de solidaridad se han mantenido dentro de los límites del grupo patrilineal, lo que ha dificultado la adopción de una iniciativa conjunta con respecto a la sociedad dominante. Pero la pertenencia a la Iglesia Filadelfia extiende las obligaciones de ayuda y confianza a todo gitano o gitana evangélicos, sea del linaje que sea. Así, se vuelven capaces de abandonar ciertas actitudes pasivas y reclamar derechos que les corresponden, como explica Wang para el caso concreto de la confiscación ilegal de mercancía a vendedores ambulantes de Madrid. Todos los gitanos que denunciaron esta práctica ilegal, confirma Wang, eran evangélicos (Wang 1989: 430-431).

Las nuevas agrupaciones étnico-religiosas gitanas experimentan un dinamismo extraordinario, aunque con altibajos, desde hace más de veinte años. Podrían estar contribuyendo indirectamente al proceso de "modernización" y de "integración" en la sociedad mayoritaria, a través del estímulo constante a la alfabetización, el rechazo a los modos delictivos de subsistencia, al robo y al engaño, el cambio de pautas en lo que refiere al cuidado personal, la gestión de la imagen, la higiene, etc. Pero esta tendencia sería al menos tan importante como la que lleva a reforzar el sentimiento de pertenencia a un grupo con una historia y una cultura únicas, o reivindicar la identidad étnica gitana que, por cierto, no tiene por qué ir inevitablemente ligada a la delincuencia, la droga, el hambre, el absentismo escolar, el aislamiento y el estigma, sino a un sentido de pertenencia que, según me sugiere el trabajo que realizo entre evangélicos gitanos, no se pierde sino que se refuerza en el seno de las nuevas agrupaciones religiosas. Y desde ese sentido de pertenencia se enfrentan a problemas tan devastadores como el de la droga, que ha generado una enorme desorientación en las familias gitanas, ya que no tienen reglas para hacer frente a un problema que inocula la división y el enfrentamiento, así como la indiferencia ante el sistema tradicional de autoridad, donde antes apenas existía: el corazón mismo de la familia gitana.

Tal vez estamos ante la clave del éxito de estas iglesias en una tierra como la andaluza, con una larga historia de asentamiento gitano, de convi- 
vencia interétnica, de mezcla y de respeto mutuo, de tolerancia y velada admiración. Esa clave podría ser la defensa y el mantenimiento a ultranza del corazón de las tradiciones gitanas en el seno de un nuevo movimiento religioso de renovación personal y comunitaria, un movimiento autogestionario que prospera con independencia del mundo no gitano (Glizer 1989). Este mantenimiento de las tradiciones se observa claramente en el caso de las fiestas: los evangélicos gitanos no reniegan de muchas de ellas ${ }^{19}$, mucho menos de la tradicional boda gitana, que mantiene la "ceremonia del pañuelo" (prueba de la virginidad de la novia) en la larga celebración que sigue a la boda evangélica en la iglesia. Es decir, la boda gitana se sigue celebrando según el rito establecido desde antiguo. En estas fiestas se bebe, aunque no en exceso, se prohiben - eso sí- las drogas, y se sigue viendo amanecer entre peladillas y alboreás ${ }^{20}$.

Falta mucho por hacer. No sobran precisamente los estudios sobre un fenómeno de vital importancia (Lagunas 1966), pero que en la Baja Andalucía parece desconcertar por igual a gitanos y a payos, quienes a veces lo consideran un movimiento ajeno a la verdadera identidad de los gitanos andaluces, extraño a las tradiciones y síntoma de una crisis sin precedentes en la historia de la cultura gitana. Se trata de diagnósticos gobernados por una concepción romántica de la identidad, por una visión reificadora de la cultura gitana. Tal vez sea hora de empezar a hablar de identidades gitanas en plural, porque no existe un único modo de ser gitano, ni tan siquiera entre los gitanos de un mismo barrio, tal vez ni entre los de una misma familia extensa. Tampoco la identidad es una pieza de cemento en la que los gitanos estén enterrados hasta las rodillas, sino un recurso, una estrategia, una construcción ideológica en sus manos para encarar la vida cotidiana y reinventar su historia, esa historia que no es sino una radiografía del presente. La identidad es también — desde el imaginario no gitano- una coartada para mantenerlos separados, para alimentar esos procesos de construcción social de la

\footnotetext{
19 Distinto es el caso de ese soberbio producto de un largo proceso de interacción y mestizaje entre gitanos y no gitanos: el flamenco. Los evangélicos no parecen muy interesados en el cante jondo y los palos del flamenco, sino en las rumbas (posiblemente por el origen catalán de muchos pioneros evangélicos) y en la canción moderna "aflamencada", un producto reciente y muy comercial. Hay gitanos conversos que afirman que el flamenco les recuerda un tipo de vida en la que las fiestas no se hacían "para mayor gloria de Dios", sino sólo por el "afán de diversión y exceso".

${ }^{20}$ Las peladillas son almendras bañadas en caramelo de diferentes colores que se compran en grandes cantidades, días antes de una boda, para ser lanzadas sobre los novios una vez realizada la ceremonia del pañuelo. Suelen ser las mujeres casadas las que se reúnen y pasan juntas el día con motivo del aprovisionamiento de peladillas para la celebración. Las alboreás son composiciones musicales muy antiguas y el cante por antonomasia de las bodas gitanas.
} 
sospecha que se abaten sobre el mundo gitano desde hace siglos. Las visiones esencialistas y reificadores de la identidad tienen gran parte de la responsabilidad en la génesis de esa visión estigmatizadora del evangelismo gitano, considerado como cosa de pobres, analfabetos, drogadictos y "gitanos de fuera".

La diversidad y el conflicto - es sorprendente que haya que recordarloestán presentes entre los gitanos no conversos y las divisiones, en cualquier caso, dan lugar a nuevos modos de relacionarse y de producir cultura e identidad. Hay que recordarlo porque muchas veces da la impresión, al leer a ciertos estudiosos ${ }^{21}$, de que los evangélicos son responsables de divisiones y conflictos desconocidos en la cultura y sociedad gitanas. Los valores centrales de la cultura gitana, que no son compartidos ni por todos ni siempre en la misma medida, no se abandonan con el cambio de religión. Tan sólo se mueven de un escenario a otro. La fuerza misma del movimiento aleluya no se entiende de espaldas a la vitalidad del pueblo gitano, y no hay más que asistir a los cultos para comprobar esto. La interpretación del protestantismo gitano como distorsionador de los valores gitanos y fuente de desunión es equivocada, y además parece dejar fuera unas identidades gitanas sumidas en profundos procesos de cambio, en ebullición, en transformación, ajenas a lo que los antropólogos quisiéramos (a veces lo parece) preservar como criaturas en ámbar.

\section{BIBLIOGRAFÍA CITADA}

Cantón Delgado, Manuela. 1996. "Curar y creer en Guatemala. A la conversión religiosa por la sanación física”, en J. A. González Alcantud y S. Rodríguez Becerra (eds.), Creer y curar. La medicina tradicional: 457-481. Granada: Diputación Provincial de Granada.

- 1998. Bautizados en fuego. Protestantes, discursos de conversión y política en Guatemala (1989-1993). Vermont: Plumsock Mesoamerican Studies.

\footnotetext{
${ }^{21}$ Me refiero a algunos autores que han tratado someramente el evangelismo gitano en Andalucía, pero esta tendencia se hace mucho más evidente al analizar la amplia bibliografía sobre las iglesias evangélicas latinoamericanas. Durante más de una década fueron consideradas por decenas de antropólogos y sociólogos como el producto de una conspiración de origen imperialista que señalaba acusadoramente a los Estados Unidos, dejando con ello a miles de indígenas y no indígenas de aquel continente convertidos en simples marionetas manejadas por oblicuos poderes que buscaban manipular sus conciencias. El proceso de reconocimiento de razones endógenas para la conversión, el análisis contextual necesario para ir más allá de los grandes diagnósticos macrosociológicos, y la cuidadosa exploración de los procesos de apropiación estratégica de religiones foráneas (cuando en cierto sentido todas lo son), ha tardado años en empezar a hacerse un lugar en los análisis (Cantón 1998).
} 
-. 1999. "Gitanos protestantes. El movimiento religioso de las iglesias Filadelfia en Andalucía". Demófilo 30: 183-206.

—. 2001. La razón hechizada. Teorias antropológicas de la religión. Barcelona: Ariel.

GAMELLA, JUAN. 1996. La población gitana en Andalucía. Un estudio exploratorio de sus condiciones de vida. Sevilla: Consejería de Trabajo y Asuntos Sociales, Junta de Andalucía.

GLIZER, RichARD. 1989. "L'Église Évangélique Tsigane comme voie possible d'un engagement culturel nouveau", en Actes du Cólloque pour le trentiénne aniversaire des Etudes Tsiganes: 433-443. París: Syros.

HERVIEU-LÉGER, DANIELlE. 1993. "La reafirmación de las minorías religiosas en Europa occidental como factor de recomposición de los espacios religiosos y políticos". Historia y Fuente Oral 10: 91-100.

JimÉNEZ RAMírez, AlFREDo. 1981. Llamamiento de Dios al pueblo gitano. Jerez de la Frontera: Talleres Gráficos de Anfra.

Jordán Pemán, Fernando. 1990. Los Aleluyas. Madrid: Secretariado Nacional Gitano.

LAGUNAS ARIAS, DAVID. 1966. "Notes sobre l'evangelisme gitano: una nova síntesi cultural". Antropologies 6: 60-67.

Marcos Montiel, Cristina. 1999. "Adicción a tu Palabra. Legitimación, deslegitimación y reinterpretación de las prácticas curativas en la Iglesia de Filadelfia", en M. Cantón, J. Prat y J. Vallverdú (coords.), Nuevos movimientos religiosos, iglesias y "sectas": 135-147. Santiago de Compostela: FAAEE y Asociación Galega de Antropoloxía.

Medina Baena, Salvador. 1999. "Ruptura y continuidad en la communitas religiosa. Un caso de escisión en la Iglesia Evangélica Filadelfia”, en M. Cantón, J. Prat y J. Vallverdú (coords.), Nuevos movimientos religiosos, iglesias y "sectas": 105-114. Santiago de Compostela: FAAEE y Asociación Galega de Antropoloxía.

Mena Cabezas, Ignacio. 1999. "Las lenguas del Espíritu: Glosolalia, identidad étnicoreligiosa y cambio cultural", en M. Cantón, J. Prat y J. Vallverdú (coords.), Nuevos Movimientos Religiosos, iglesias y "sectas": 123-133. Santiago de Compostela: FAAEE y Asociación Galega de Antropoloxía.

PujADAS, JuAn J. 1992. El método biográfico. El uso de las bistorias de vida en Ciencias Sociales. Madrid: Centro de Investigaciones Sociológicas.

SAN ROMÁN, TERESA. 1997. La diferencia inquietante. Viejas y nuevas estrategias culturales de los gitanos. Madrid: Siglo XXI.

WANG, KIRSTEN. 1989. "Le mouvement pentecostiste chez les gitans espagnols", en Actes du Cólloque pour le trentiénne anniversaire des Etudes Tsiganes: 423-433. París: Syros. Weber, Max. 1989. La ética protestante y el espíritu del capitalismo. Barcelona: Península. - 1996. "La ciencia como vocación", en El político y el científico: 180-231. Madrid. 